\title{
Twenty years of surveillance for Eastern equine encephalitis virus in mosquitoes in New York State from 1993 to 2012
}

JoAnne Oliver ${ }^{1,2^{*}}$, Gary Lukacik ${ }^{3}$, John Kokas ${ }^{4}$, Scott R. Campbell ${ }^{5}$, Laura D. Kramer ${ }^{6,7}$, James A. Sherwood ${ }^{1}$ and John J. Howard ${ }^{1}$

\begin{abstract}
Background: The year 1971 was the first time in New York State (NYS) that Eastern equine encephalitis virus (EEEV) was identified in mosquitoes, in Culiseta melanura and Culiseta morsitans. At that time, state and county health departments began surveillance for EEEV in mosquitoes.

Methods: From 1993 to 2012, county health departments continued voluntary participation with the state health department in mosquito and arbovirus surveillance. Adult female mosquitoes were trapped, identified, and pooled. Mosquito pools were tested for EEEV by Vero cell culture each of the twenty years. Beginning in 2000, mosquito extracts and cell culture supernatant were tested by reverse transcriptase-polymerase chain reaction (RT-PCR).

Results: During the years 1993 to 2012, EEEV was identified in: Culiseta melanura, Culiseta morsitans, Coquillettidia perturbans, Aedes canadensis (Ochlerotatus canadensis), Aedes vexans, Anopheles punctipennis, Anopheles quadrimaculatus, Psorophora ferox, Culex salinarius, and Culex pipiens-restuans group. EEEV was detected in 427 adult mosquito pools of 107,156 pools tested totaling 3.96 million mosquitoes. Detections of EEEV occurred in three geographical regions of NYS: Sullivan County, Suffolk County, and the contiguous counties of Madison, Oneida, Onondaga and Oswego. Detections of EEEV in mosquitoes occurred every year from 2003 to 2012, inclusive. EEEV was not detected in 1995, and 1998 to 2002, inclusive.

Conclusions: This was the first time in NYS that EEEV was detected in CX. salinarius, Ps. ferox and An. punctipennis. The detection of EEEV in mosquitoes every year for 10 years was the longest time span since surveillance began in 1971. The calendar date of the earliest annual appearance of EEEV in mosquitoes did not change during surveillance spanning 42 years.
\end{abstract}

Keywords: Eastern equine encephalitis virus, Aedes, Anopheles, Coquillettidia, Culex, Culiseta, Ochlerotatus, Psorophora, New York State

\section{Background}

Culiseta melanura (Coquillett) becomes infected by, and transmits, Eastern equine encephalitis virus (EEEV) during blood feeding [1]. This species feeds preferentially on birds and opportunistically on mammals $[2,3]$ and occasionally on humans $[4,5]$. Other genera and species of mosquitoes common in the northeastern USA have

\footnotetext{
* Correspondence: JoAnne.Oliver@health.ny.gov

'Department of Health, Central New York Regional Office, State of New York, 217 South Salina Street, Syracuse, NY 13202, USA

${ }^{2}$ School of Agriculture and Natural Resources, Morrisville State College, State University of New York, 80 Eaton Street, Morrisville, NY 13408, USA Full list of author information is available at the end of the article
}

been found to carry EEEV and have been thought to play a role in the transmission of EEEV, including Coquillettidia perturbans (Walker) [6], Aedes canadensis (Theobald) (Ochlerotatus canadensis) [7-9], and Aedes cinereus Meigen $[9,10]$.

In 1971, the first reported case of Eastern equine encephalitis (EEE) in a human in New York State (NYS), in Oswego County [11], prompted the respective health departments to begin annual surveillance for EEEV in mosquitoes [7, 11-13]. In 1971, EEEV was identified in Cs. melanura, Culiseta morsitans (Theobald), and Culex restuans Theobald, in Oswego County [11, 12]. In 1973,

(c) The Author(s). 2018 Open Access This article is distributed under the terms of the Creative Commons Attribution 4.0 International License (http://creativecommons.org/licenses/by/4.0/), which permits unrestricted use, distribution, and 
EEEV was identified in Culex pipiens Linnaeus, in Suffolk County [13, 14]. In 1974, EEEV was identified in Ae. canadensis in Oswego County [12]. In 1976, EEEV was identified in Cq. perturbans in Oswego County [13]. In 1978, EEEV was identified in Cs. melanura, in Suffolk County (Howard JJ, Oliver J, Guirgis S, Woodall JP. Eastern equine encephalitis in Suffolk County, Long Island, New York, 1994. Proceedings of the 82nd Annual Meeting New Jersey Mosquito Control Association 1995;82:12-16) [14, 15]. In 1990, EEEV was identified in Aedes vexans (Meigen) and Anopheles quadrimaculatus Say [16].

From 1971 to 1992, there were detections of EEEV in eight mosquito species within five genera, in NYS [7]; in order of frequency, 159 were from Cs. melanura, 18 from Cs. morsitans, 11 from Cq. perturbans, nine from Ae. canadensis, two from Ae. vexans, and one each from $A n$. quadrimaculatus, $C x$. pipiens, and from $C x$. restuans.

The purpose of this work is to report on continued surveillance for EEEV in mosquitoes in NYS, from 1993 to 2012 .

\section{Methods}

\section{Recruitment of counties}

Counties decided to participate in mosquito and arbovirus surveillance based on local concern about vector-borne disease and budget. The number of counties that conducted mosquito surveillance and submitted mosquito specimens for virus assay ranged from nine to 43 from 1993 to 2012 (Table 1) [17]. There are 57 counties in NYS exclusive of the five counties that comprise New York City (NYC). In NYC, the Department of Health and Mental Hygiene conducted their own surveillance and testing and their results are not included in this present study.

\section{Trapping of mosquitoes}

Trapping of adult mosquitoes began in May of each year and ended by October. Mosquitoes were collected using light traps supplemented with dry ice [18], gravid traps [19], or diurnal resting boxes [20]. Counties selected trap types depending on which viruses and mosquito species they were interested in collecting. Counties focusing on EEEV used diurnal resting boxes, optimal for collecting Culiseta, and light traps, optimal for Aedes and Coquillettidia. Counties focusing on West Nile virus (WNV) used gravid traps, optimal for collecting Culex, and light traps [21]. The geographical distribution of EEE or EEEV in the recent past $[14,16]$ or of $\mathrm{WNV}[17,22]$ was used to determine the locations of surveillance sites in the current study.

\section{Identification and sorting of mosquitoes}

The identification of adult mosquito specimens was aided with microscopy and based on morphologic features and
Table 1 Number of counties conducting surveillance for mosquitoes and Eastern equine encephalitis virus in New York State from 1993 to 2012

\begin{tabular}{ll}
\hline Year & No. of participating counties \\
\hline 1993 & 9 \\
1994 & 9 \\
1995 & 9 \\
1996 & 9 \\
1997 & 9 \\
1998 & 9 \\
1999 & 9 \\
2000 & 21 \\
2001 & 43 \\
2002 & 39 \\
2003 & 29 \\
2004 & 29 \\
2005 & 27 \\
2006 & 32 \\
2007 & 26 \\
2008 & 23 \\
2009 & 15 \\
2010 & 15 \\
2011 & 14 \\
2012 & 13 \\
\hline
\end{tabular}

nomenclature from published methods [23-26]. Male mosquitoes were excluded. When possible, identifications were made to species level. Some identifications were made to group level (Table 2). Each county decided which mosquito species to submit for testing. Females were sorted by species, by physiological status (unfed, blood-fed, gravid), collection site, type of trap, and week. Appropriately sorted specimens were then pooled. Based on methodology, the laboratory decided on the number of mosquitoes per pool. During the years 1993 to 1999, the number of mosquito specimens per pool was 10-100; during 2000 to 2008, 10-50; and during 2009 to 2012, 10-60. Each year, the testing laboratory, based on capacity, determined a total number of pools they would be able to accept from each county.

\section{Testing mosquitoes for virus}

From 1993 to 1999, pools of mosquitoes were tested for virus by Vero cell culture (African green monkey kidney cells), according to the method of Srihongse et al. [13] as modified by Boromisa \& Grayson [27]. From 2000 to 2012, pools of mosquitoes were tested for virus by amplification of viral nucleic acid [22]. Pools were placed in 2-ml polypropylene microcentrifuge tubes containing a zinc-plated steel bead (Daisy Outdoor Products, Rogers, 
Table 2 Mosquitoes collected and tested for Eastern equine encephalitis virus in New York State from 1993 to 2012

\begin{tabular}{|c|}
\hline Species \\
\hline Aedes (Ochlerotatus) canadensis (Theobald) \\
\hline Aedes (Aedes) cinereus Meigen \\
\hline Aedes (Aedimorphus) vexans (Meigen) \\
\hline Aedes (Finlaya) japonicus (Theobald) \\
\hline Aedes (Ochlerotatus) abserratus-punctor group ${ }^{a}$ \\
\hline Aedes (Ochlerotatus) abserratus (Felt \& Young) \\
\hline Aedes (Ochlerotatus) punctor (Kirby) \\
\hline Aedes (Ochlerotatus) atropalpus (Coquillett) \\
\hline Aedes (Ochlerotatus) cantator (Coquillett) \\
\hline Aedes (Ochlerotatus) dorsalis (Meigen) \\
\hline Aedes (Ochlerotatus) communis group ${ }^{a}$ \\
\hline Aedes (Ochlerotatus) abserratus (Felt \& Young) \\
\hline Aedes (Ochlerotatus) communis (De Geer) \\
\hline Aedes (Ochlerotatus) provocans (Walker) \\
\hline Aedes (Ochlerotatus) punctor (Kirby) \\
\hline Aedes (Ochlerotatus) sticticus (Meigen) \\
\hline Aedes (Ochlerotatus) grossbecki Dyar \& Knab \\
\hline Aedes (Ochlerotatus) implicatus Vockeroth \\
\hline Aedes (Ochlerotatus) intrudens Dyar \\
\hline Aedes (Ochlerotatus) riparius Dyar \& Knab \\
\hline Aedes (Ochlerotatus) sollicitans (Walker) \\
\hline Aedes (Ochlerotatus) spencerii (Theobald) \\
\hline Aedes (Ochlerotatus) stimulans group ${ }^{a}$ \\
\hline Aedes (Ochlerotatus) excrucians (Walker) \\
\hline Aedes (Ochlerotatus) fitchii (Felt \& Young) \\
\hline Aedes (Ochlerotatus) stimulans (Walker) \\
\hline Aedes (Ochlerotatus) taeniorhynchus (Wiedemann) \\
\hline Aedes (Ochlerotatus) triseriatus (Say) \\
\hline Aedes (Ochlerotatus) trivittatus (Coquillett) \\
\hline Aedes (Stegomyia) albopictus (Skuse) \\
\hline Anopheles (Anopheles) earlei Vargas \\
\hline Anopheles (Anopheles) punctipennis (Say) \\
\hline Anopheles (Anopheles) quadrimaculatus Say \\
\hline Anopheles (Anopheles) walkeri Theobald \\
\hline Coquillettidia (Coquillettidia) perturbans (Walker) \\
\hline Culex (Culex) pipiens-restuans group ${ }^{a}$ \\
\hline Culex (Culex) pipiens Linnaeus \\
\hline Culex (Culex) restuans Theobald \\
\hline Culex (Culex) salinarius Coquillett \\
\hline Culex (Neoculex) territans Walker \\
\hline Culiseta (Climacura) melanura (Coquillett) \\
\hline Culiseta (Culicella) morsitans (Theobald) \\
\hline Culiseta (Culicella) minnesotae Barr \\
\hline
\end{tabular}

Table 2 Mosquitoes collected and tested for Eastern equine encephalitis virus in New York State from 1993 to 2012 (Continued)

Species

Culiseta (Culiseta) impatiens (Walker)

Culiseta (Culiseta) inornata (Williston)

Orthopodomyia (Orthopodomyia) signifera (Coquillett)

Orthopodomyia (Orthopodomyia) alba Baker

Psorophora (Grabhamia) columbiae (Dyar \& Knab)

Psorophora (Janthinosoma) ferox (Humboldt)

Psorophora (Janthinosoma) mathesoni Belkin \& Heinemann

Psorophora (Psorophora) ciliata (Fabricius)

Toxorhynchites (Lynchiella) rutilus septentrionalis (Dyar \& Knab)

ranotaenia (Uranotaenia) sapphirina (Osten Sacken)

${ }^{a}$ Groups may contain the species indented below the group name

Arkansas, USA), kept on dry ice, and tested at the Arbovirus Laboratory, Wadsworth Center, Department of Health, State of New York, in Albany. Every year, a portion was tested for the presence of arboviruses by screening on Vero cell culture [28]. If cytopathology was observed, cell culture supernatant was tested for EEEV by a specific reverse-transcription polymerase chain reaction (RT-PCR) [29] as previously used in our Arbovirus Laboratory [28, 30]. RT-PCR was also conducted on the original mosquito pool homogenate $[28,30]$. In detail, two sets of primers and probes, each targeting a different region of the EEEV RNA template, were used for testing specimens. First, sequences for the set targeting the E2 gene were provided by the Centers for Disease Control and consisted of forward primer 5'-ACA CCG CAC CCT GAT TTT ACA-3', reverse primer 5'-CTT CCA AGT GAC CTG GTC GTC-3', and probe 5'-6FAM-TGC ACC CGG ACC ATC CGA CCT-TAMRA-3' [31]. A second set was developed in the Viral Encephalitis Laboratory of the Wadsworth Center of NYSDOH and targeted the E1 gene (forward primer 5'-ACA CTA AAT TCA CCC TAG TTC GAT-3', reverse primer 5'-GTG TAT AAA ATT ACT TAG GAG CAG CAT TAT G-3', and probe 5'-6FAM-CGA GCT ATG GTG ACG GTG GTG CA-TAMRA-3' [30]. Assays were performed on the ABI Prism 7000 or 7500 sequence detectors using ABI TaqMan one-step RT-PCR master mix (Applied Biosystems, Foster City, California, USA). Standards were prepared from RNA extracted from EEEV stock that had been amplified on Vero cells and titers determined [28]. Thermal cycling consisted of $48{ }^{\circ} \mathrm{C}$ for $30 \mathrm{~min}$ for $\mathrm{RT}, 95{ }^{\circ} \mathrm{C}$ for $10 \mathrm{~min}$, and 40 cycles of $95{ }^{\circ} \mathrm{C}$ for $15 \mathrm{~s}$ and $60{ }^{\circ} \mathrm{C}$ for one min. A sample was considered positive if the $\mathrm{C}_{\mathrm{T}}$ value was less than 40 for both primer sets, and the $\Delta R n$ value was more than five times the average $\Delta \mathrm{Rn}$ values for the negative controls. 
Results were expressed in $C_{T}$ values or relative numbers of plaque forming units (PFU) calculated by linear regression from the standard curve. Pools are processed for EEEV within three to four days of receipt. The EEEV assay had a sensitivity of five gene copies per reaction [30]. Pools of $C x$. pipiens and $C x$. restuans were not inoculated onto Vero cells unless EEEV was detected by RT-PCR.

\section{Results}

\section{Mosquito specimens}

From 1993 to 2012, statewide, 3.96 million mosquitoes were submitted and assayed (Fig. 1). Of the approximately 70 species of mosquitoes previously known to be present in NYS [23, 24], 49 species were submitted for arbovirus testing (Table 2). There were 11 species of mosquitoes in which EEEV was detected (Table 3). State-wide, Cs. melanura accounted for $8.43 \%(333,871$ of $3,960,070$ ) of mosquitoes submitted.

From 2001 through 2012, in the four counties of Madison, Oneida, Onondaga and Oswego, Cq. perturbans, Cs. melanura and Ae. canadensis accounted for $33 \%, 17 \%$ and $16 \%$, respectively, of all mosquitoes submitted for arbovirus testing. From 2001 through 2012, in Suffolk County, Cx. pipiens-restuans group, Cs. melanura, Aedes sollicitans (Walker) and Ae. vexans accounted for $68 \%, 5 \%, 5 \%$ and $4 \%$, respectively, of all mosquitoes submitted for arbovirus testing.

Whether the number of participating counties was smaller $(n=9)$ or larger $(n=43)$ (Table 1$)$, EEEV was not detected in mosquitoes in the years 1998 to 2002 (Table 4).

\section{Mosquito pools}

The 3.96 million mosquitoes were assayed in 107,156 pools (Table 4). One to two percent of samples testing positive for EEEV by RT-PCR were not infectious on Vero cell culture. There were 14 of 20 years with EEEV detected in mosquitoes (Table 4). In those 14 years, the percent positive pools ranged between $0.02-1.66 \%$ (mean 0.54\%) (Table 4). For Cs. melanura alone, there were 14 of 20 years with EEEV detected in mosquitoes, ranging between $0.01-14.63 \%$ (mean 5.77\%) (Table 4). Over the 20 years, the total number of mosquitoes and the total number of pools were within the same order of magnitude (Table 4, Fig. 1).

Detections were made in the following mosquito species: Cs. melanura, Cs. morsitans, Cq. perturbans, Ae. canadensis, Ae. vexans, Anopheles punctipennis (Say), An. quadrimaculatus, Psorophora ferox (Humboldt), Culex salinarius Coquillett and Cx. pipiens-restuans group.

Culiseta melanura accounted for 91\% (388 of 427) of pools in which EEEV was detected (Table 4). The number of Cs. melanura pools assayed, and the numbers of pools testing positive for EEEV, each year in NYS from 1993 to 2012, is illustrated in Fig. 2. Species other than Cs. melanura accounted for 9\% (39 of 427) of pools in which EEEV was detected (Table 4).

From 1993 to 1999, when pool sizes ranged from 10 to 100 specimens, the average pool size was 61 specimens per pool. From 2000 to 2008, when pool sizes ranged from 10 to 50 , the average pool size was 30 specimens per pool. From 2009 to 2012, when pool sizes ranged from 10 to 60 , the average pool size was 35 specimens

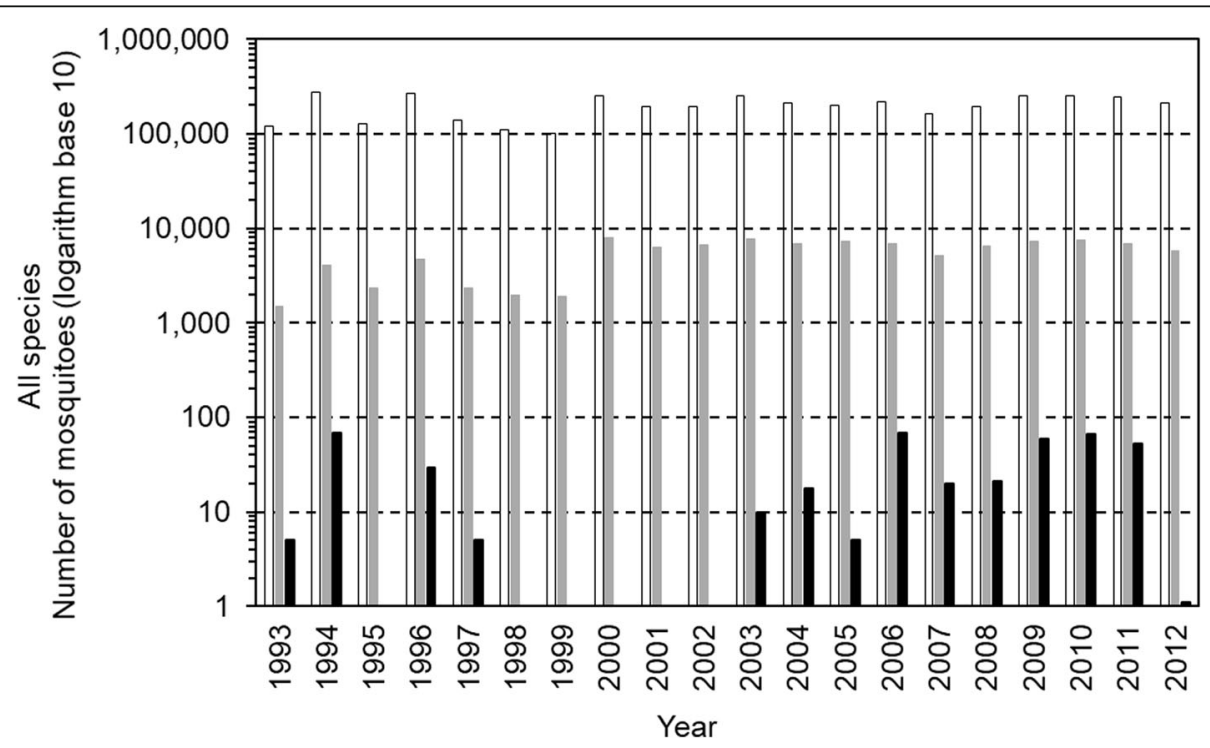

Fig. 1 Detections of Eastern equine encephalitis virus in all species of mosquitoes. Bars show the number of mosquitoes submitted (white bars), the number of pools tested (gray bars) and the number of pools positive (black bars), 1993 to 2012, in New York State. From 1993 to 1999,2000 to 2008, and 2009 to 2012, average pool sizes were 61, 30 and 35, respectively 


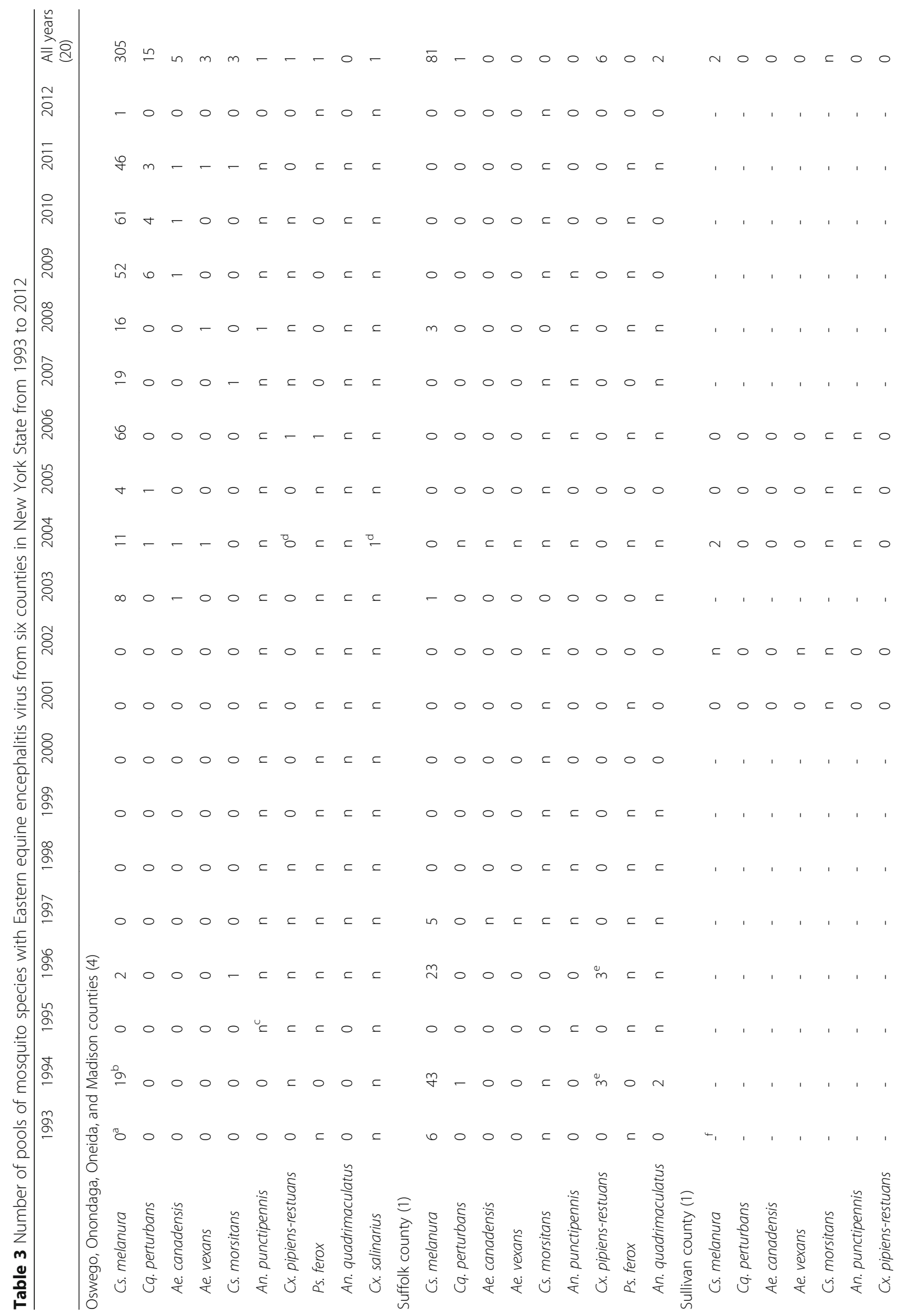




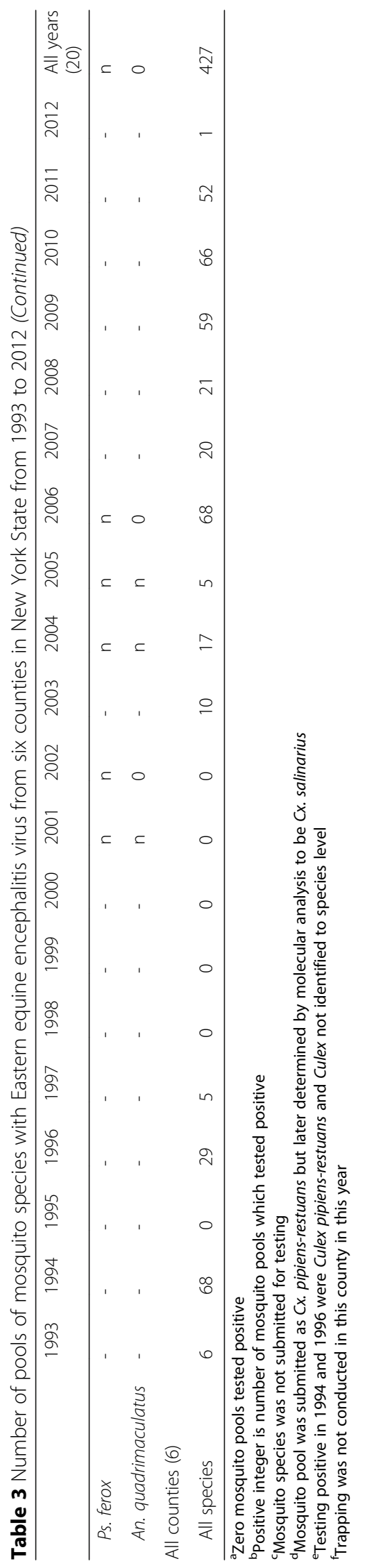


Table 4 Mosquito specimens pooled and tested for Eastern equine encephalitis virus in New York State, 1993 to 2012

\begin{tabular}{|c|c|c|c|c|c|c|}
\hline \multirow[t]{2}{*}{ Year } & \multicolumn{3}{|c|}{ All mosquito species ${ }^{a}$} & \multicolumn{3}{|l|}{ Cs. melanura } \\
\hline & No. of specimens & No. of pools & No. of EEEV-positive pools (\%) & No. of specimens & No. of pools & No. of EEEV-positive pools (\%) \\
\hline $1993^{b}$ & 119,280 & $1482^{b}$ & $6(0.34)$ & 67,165 & $1013^{b}$ & $6(0.5)$ \\
\hline 1994 & 275,262 & 4101 & $68(1.66)$ & 43,584 & 735 & $62(8.4)$ \\
\hline 1995 & 127,866 & 2301 & 0 & 12,245 & 449 & 0 \\
\hline 1996 & 266,685 & 4659 & $29(0.62)$ & 22,766 & 668 & $25(0.04)$ \\
\hline 1997 & 140,189 & 2358 & $5(0.21)$ & 19,834 & 512 & $5(0.01)$ \\
\hline 1998 & 111,140 & 1954 & 0 & 19,322 & 385 & 0 \\
\hline 1999 & 102,755 & 1911 & 0 & 9056 & 319 & 0 \\
\hline $2000^{c}$ & 252,003 & $7871^{c}$ & 0 & 14,529 & $395^{c}$ & 0 \\
\hline 2001 & 191,981 & 6360 & 0 & 11,349 & 361 & 0 \\
\hline 2002 & 194,906 & 6738 & 0 & 6524 & 222 & 0 \\
\hline 2003 & 249,554 & 7714 & $10(0.13)$ & 9190 & 286 & $9(3.15)$ \\
\hline 2004 & 209,362 & 6773 & $17(0.26)$ & 10,255 & 302 & $13(4.63)$ \\
\hline 2005 & 196,371 & 7178 & $5(0.07)$ & 4976 & 199 & $4(2.01)$ \\
\hline 2006 & 216,924 & 6895 & 68 (0.99) & 16,111 & 482 & 66 (13.69) \\
\hline 2007 & 160,886 & 5155 & $20(0.39)$ & 9654 & 330 & 19 (5.76) \\
\hline 2008 & 194,988 & 6509 & $21(0.32)$ & 9785 & 347 & 19 (5.48) \\
\hline $2009^{d}$ & 250,396 & $7191^{d}$ & $59(0.82)$ & 15,189 & $440^{d}$ & $52(11.82)$ \\
\hline 2010 & 249,120 & 7409 & $66(0.89)$ & 12,849 & 417 & $61(14.63)$ \\
\hline 2011 & 241,447 & 6767 & $52(0.77)$ & 11,725 & 446 & $46(10.31)$ \\
\hline 2012 & 208,955 & 5830 & $1(0.02)$ & 7763 & 298 & $1(0.34)$ \\
\hline Total & $3,960,070$ & 107,156 & 427 & 333,871 & 8606 & 388 \\
\hline
\end{tabular}

${ }^{a}$ Mosquito species submitted for arboviral testing include Cs. melanura

${ }^{b}$ Pool sizes were 10-100 mosquito specimens from 1993 to 1999

cPool sizes were 10-50 mosquito specimens from 2000 to 2008

${ }^{\mathrm{d}}$ Pool sizes were 10-60 mosquito specimens from 2009 to 2012

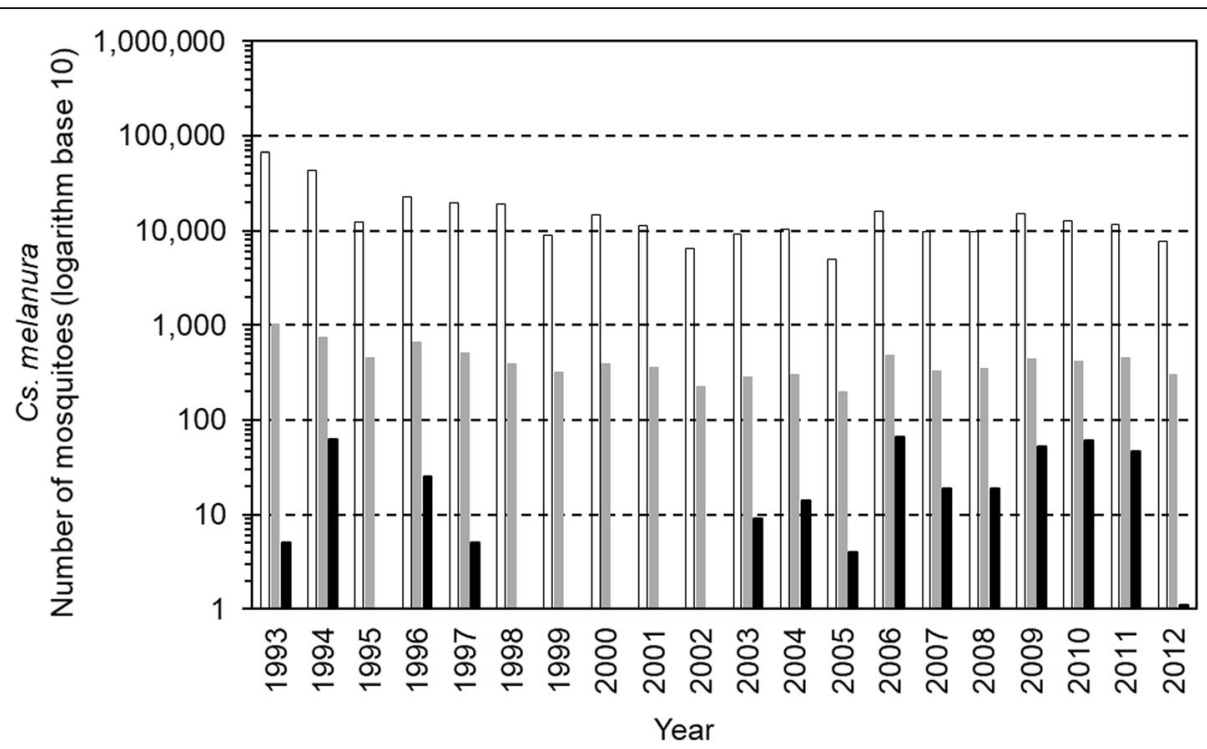

Fig. 2 Detections of Eastern equine encephalitis virus in Culiseta melanura mosquitoes. Bars show the number of mosquitoes submitted (white bars), the number of pools tested (gray bars) and the number of pools positive (black bars), 1993 to 2012, in New York State. From 1993 to 1999, 2000 to 2008, and 2009 to 2012, average pool sizes were 43, 31 and 29, respectively 
per pool. For Cs. melanura, the average pool sizes during these periods were 43,31 and 29 , respectively.

\section{Geographical distribution of mosquitoes with virus}

Six counties had mosquitoes that tested positive for $\mathrm{EEEV}$, and these counties were located in three geographical regions of NYS (Table 3).

First, in Madison, Oneida, Onondaga and Oswego Counties, which all have Oneida Lake as a border, EEEV was detected in eight species of mosquitoes and $C x$. pipiens-restuans group, among 27 species tested from this region. This area yielded $23 \%(25,071$ of 107,156$)$ of all mosquito pools, and $78 \%$ (335 of 427) of all EEEV-positive pools. This area also yielded 79\% (305 of 388) of all Cs. melanura pools that were EEEV-positive, and $77 \%$ (30 of 39) of all pools other than Cs. melanura that were EEEV-positive.

Secondly, in Suffolk County, EEEV was detected in three mosquito species and one group (Table 3). There were 90 pools in which EEEV was detected, consisting of 81 pools of Cs. melanura, six of Cx. pipiens-restuans group, two of An. quadrimaculatus and one of Cq. perturbans. The easternmost location in NYS in which EEEV was detected was the Town of East Hampton, Suffolk County.

Thirdly, in Sullivan County, EEEV was detected in one species of mosquito, Cs. melanura, in two pools, in the Town of Thompson (Table 3).

\section{Timing of mosquitoes with virus}

EEEV was detected in mosquitoes in 1993 through 1997, and in 2003 through 2012 (Fig. 1), within at least one of these three regions of NYS. However, EEEV was not detected in all three regions in the same years, during the 20 years of surveillance. EEEV was not detected in mosquitoes in 1995, and 1998 through 2002 (Table 4, Fig. 1). This pattern was the same with Cs. melanura alone (Table 4, Fig. 2). EEEV was detected at least once in each of the nine species of mosquitoes and the $C x$. pipiens-restuans group (Table 3). There was no year during which EEEV was detected simultaneously in all nine species of mosquitoes and the Cx. pipiens-restuans group (Table 3).

State-wide, the earliest date in any year that EEEV was detected was June 25 (2007), in Oswego County, and was July 7 (1994), in Suffolk County, and was September 2 (2004), in Sullivan County, all in Cs. melanura. Within the 20-year period, detections of EEEV occurred in June $(n=2)$, July $(n=81)$, August $(n=234)$, September $(n=108)$ and October $(n=2)$ (Table 5).

It was in 1996 and 2003 that EEEV in mosquitoes was detected in the most easterly area of NYS, in the Town of East Hampton, Suffolk County on Long Island. It was in 2004 that EEEV in mosquitoes was detected in a
Table 5 Years and months of detections of Eastern equine encephalitis virus in mosquitoes during surveillance in New York State from 1993 to 2012

\begin{tabular}{lllllll}
\hline Year & June & July & August & September & October & Total \\
\hline 1993 & 0 & 0 & 4 & 0 & 2 & 6 \\
1994 & 0 & 13 & 35 & 20 & 0 & 68 \\
1995 & 0 & 0 & 0 & 0 & 0 & 0 \\
1996 & 0 & 4 & 17 & 8 & 0 & 29 \\
1997 & 0 & 0 & 3 & 2 & 0 & 5 \\
1998 & 0 & 0 & 0 & 0 & 0 & 0 \\
1999 & 0 & 0 & 0 & 0 & 0 & 0 \\
2000 & 0 & 0 & 0 & 0 & 0 & 0 \\
2001 & 0 & 0 & 0 & 0 & 0 & 0 \\
2002 & 0 & 0 & 0 & 0 & 0 & 0 \\
2003 & 0 & 0 & 2 & 8 & 0 & 10 \\
2004 & 0 & 2 & 7 & 8 & 0 & 17 \\
2005 & 0 & 4 & 1 & 0 & 0 & 5 \\
2006 & 0 & 10 & 44 & 14 & 0 & 68 \\
2007 & 1 & 15 & 2 & 2 & 0 & 20 \\
2008 & 0 & 0 & 10 & 11 & 0 & 21 \\
2009 & 0 & 12 & 33 & 14 & 0 & 59 \\
2010 & 1 & 14 & 41 & 10 & 0 & 66 \\
2011 & 0 & 7 & 34 & 11 & 0 & 52 \\
2012 & 0 & 0 & 1 & 0 & 0 & 1 \\
\hline & & & & & & \\
\hline
\end{tabular}

southerly mainland area of NYS, in the Town of Thompson, Sullivan County.

\section{Discussion}

Surveillance

In this arbovirus surveillance program, the number of individual mosquitoes and number of pools submitted annually remained consistent (Table 4, Fig. 1).

Among 57 counties in NYS (excluding NYC), between nine and 43, inclusive, participated in annual mosquito submission. The introduction of WNV to NYS in 1999 [31] resulted in more counties (range 13-43, average 25) opting to conduct mosquito and arbovirus surveillance, beginning in 2000 [17]. Testing mosquitoes from a greater number of counties did not result in more detections of EEEV, as detections of EEEV occurred in only six counties.

\section{Species of mosquitoes with virus}

In NYS, this was the first time that the mosquito species Cx. salinarius, Ps. ferox, and An. punctipennis were found to have EEEV (Table 3).

The preponderance of detections of EEEV being in Cs. melanura is expected due to the importance of ornithophilic mosquito species such as Culiseta to maintain 
EEEV in a mosquito-wild bird cycle and the ecological setting where EEEV is present. Given the large percentage of Cs. melanura having EEEV, it is to be expected that the greater the number of Cs. melanura collected, the greater the number of pools having EEEV in years when EEEV is present (Fig. 2).

The preponderance of detections of EEEV being from mosquitoes collected in Madison, Oneida, Onondaga and Oswego Counties is consistent with the history of EEEV detections, observed from 1971 to 1992 [7, 11, 32].

In aggregate, from 1971 to 2012, in NYS there were 629 detections of EEEV in 11 mosquito species within seven genera. In order of frequency, 547 were from Cs. melanura, 27 from Cq. perturbans, 21 from Cs. morsitans, 14 from Ae. canadensis, seven from Cx. pipiens-restuans group, five from Ae. vexans, three from An. quadrimaculatus, and one each from $C x$. pipiens, $C x$. restuans, $C x$. salinarius, Ps. ferox and An. punctipennis.

\section{Geographical distribution of mosquitoes with virus} During the period of 1971 to 1992, inclusive, four contiguous counties (Madison, Oneida, Onondaga and Oswego), have had more detections of EEEV in mosquitoes than any other location in NYS $[7,16]$. This trend continued from 2003 to 2012.

In Suffolk County, EEEV was first detected in mosquitoes in 1973 [14]. Suffolk County is the easternmost county in NYS that EEEV was detected (Town of East Hampton), in 1996 and 2003. The neighboring state of Rhode Island reported one case of human EEE, on Block Island (in Washington County) in 1993 and 71 detections of EEEV in 1996, 1997, 1998 and 2000 in Cs. melanura, Cq. perturbans, Ae. canadensis and Ae. vexans and unidentified Anopheles species and Culex species in Washington County and Newport County [33, 34]. These detections in Rhode Island are comparable to our detections in Suffolk County during that time (Table 3). The coast of Block Island is $22 \mathrm{~km}$ off the northeast coast of Suffolk County. The neighboring state of Connecticut reported EEEV in eight mosquito species in New London County in 1996 [35], again comparable to our detections in Suffolk County in the period 1993 to 1997 (Table 3). The coast of New London County is 13 $\mathrm{km}$ off the northern coast of Suffolk County.

In Sullivan County, EEEV was first detected in mosquitoes in 2004, before which time EEEV had not been reported in mosquitoes or vertebrates. In the Town of Thompson in Sullivan County, EEEV was detected in Cs. melanura (Table 3), collected on September 2, 2004. Sullivan County had its first case in an eagle on September 7, 2004 and its first case in a horse on October 3, 2004 [36]. One of these cases was located $1 \mathrm{~km}$ from where the EEEV-infected Cs. melanura were collected. In adjacent Ulster County, there was a case in a horse on September 15, 2004 and a case in a goldfinch on October 19, 2004 [36].

\section{Timing of mosquitoes with virus}

In NYS, detection of EEEV in mosquitoes every year from 2003 to 2012, inclusive, was the longest consecutive time period, to date. During the 20 -year period from 1993 to 2012, there was a five-year period from 1998 to 2002 without detection of EEEV in mosquitoes.

In Madison, Oneida, Onondaga and Oswego Counties, during the 22-year period from 1971 to 1992, there was a three-year interval, from 1984 to 1986 , without detection of EEEV in mosquitoes [7, 16]. From 1993 to 2012, EEE in humans was reported in only Onondaga or Oswego counties, in 2009, 2010 and 2011 [36].

In 2003 concomitantly, in Suffolk County, there were EEEV-infected mosquitoes and an EEE case in a horse [36]. In other years when there were detections of EEEV in mosquitoes, specifically 1993, 1994, 1996, 1997 and 2008, there were no cases of EEE in horses or other vertebrates reported in Suffolk County [36].

In Massachusetts, EEEV was detected in mosquitoes every year from 1968 to 1980 and 1982 to 1993 [37, 38] and every year from 1997 to 2001 [38]. In New Jersey, EEEV was detected in mosquitoes every year from 2003 to 2010 [39]. In Connecticut, EEEV was detected in mosquitoes every year from 2009 to 2013 [40].

The calendar date of the earliest seasonal detection of EEEV in mosquitoes was June 25, in 1991, during the previous 22-year surveillance period of 1971 to 1992 $[7,16]$. The calendar date of the earliest seasonal detection of EEEV in mosquitoes was also June 25, in 2007, during the present 20-year surveillance period of 1993 to 2012.

The finding of only two detections in October (Table 5) is consistent with the natural seasonal decrease in active adult mosquitoes in NYS, the typical onset of mosquito-killing frosts and the conclusion of seasonal mosquito surveillance programs.

\section{Transmission of EEEV from mosquitoes}

Theoretically, any of the 11 mosquito species testing positive for EEEV may play a role in transmission to mammals. Hayes \& Doane [41] proposed a role for Cs. melanura in transmission to mammals. Culiseta melanura has a higher percentage of specimens carrying EEEV than any other mosquito species [42], which has been used to argue for the involvement of this species in enzootic [1] and epidemic [16] transmission of EEEV. The identification of human blood in field-caught Cs. melanura has been used to argue for the involvement of this species in transmission of EEEV to humans [4, 5]. Aedes albopictus (Skuse), Ae. vexans, Ae. canadensis and Cq. perturbans, have been shown to carry EEEV [8]. 
Culex salinarius, Ps. ferox and An. punctipennis may feed on humans [24]. Culex salinarius, Ps. ferox and An. punctipennis can seek hosts during the usual season of EEE disease in NYS, which has been July to October [7, 32, 36]. EEEV was detected in Cx. salinarius and Ps. ferox in Mississippi in 1998, 1999 and 2002 [43]. EEEV was detected in An. punctipennis in South Carolina between 1996 and 1998 [44]. EEEV was detected in Cx. salinarius in Ohio state in 1991 concomitantly with cases of EEE in horses [45]. Culex salinarius and An. punctipennis are considered likely vectors of EEE in Massachusetts [46]. Vaidyanathan et al. [47] found Cx. salinarius and An. punctipennis to be susceptible to infection with EEEV via mouth parts and found these species to have potential for salivary transmission. Psorophora ferox is a known vector of Venezuelan equine encephalitis virus (VEEV) [48], which suggests Ps. ferox has the potential to transmit EEEV.

\section{Practical applications}

During this surveillance, every year, in the usual course of official duty, the state health department presented information on the presence of mosquitoes with EEEV to the appropriate officials in the affected counties. The officials, pursuant to public health code, made decisions on when and how to prevent disease by implementing a public health information campaign via newspapers, radio, television or web sites. Also, officials decided when and how to implement vector control using mosquito adulticides in affected geographical areas. The state health department presented this information on the presence of mosquitoes with EEEV to practicing veterinarians to consider prevention, such as vaccination and to consider the diagnosis of EEE.

\section{Limitations of this study}

This study was not able to determine the latest date in the year that EEEV was present in mosquitoes, because the county and state mosquito surveillance programs ceased in October. Each county health department made its own decision to participate, or not, in surveillance. The number of participating counties varied from year to year. Counties could not submit all collected mosquitoes, due to testing capacity. The collected mosquitoes that were not submitted may have contained EEEV. Choices of trap types by each county may be viewed as sampling bias, because different traps attract different species to different extents. EEE disease in vertebrate animals, including humans, was reported in 15 counties during 2003 to 2012 [36]. Of these 15 counties, 11 to 12 counties did routine annual adult mosquito surveillance; two counties did no surveillance.
During years 2000 to 2008, when the emergence of WNV was a concern, more counties participated (Table 1). Nevertheless, each year, similar numbers of mosquitoes were submitted, and similar numbers of pools were made and tested for the presence of EEEV in mosquitoes (Table 4 and Fig. 1).

Vero cell culture testing may fail to detect virus, if the specimen is degraded, or the virus is not viable. RT-PCR testing may fail to detect virus, if the specimen is degraded, or there is an unrecognized mutation in the virus. In 2000, RT-PCR was established for surveillance of WNV in mosquitoes following the introduction to NYS of WNV disease. This allowed for EEV to be tested by RT-PCR, along with WNV, in a single multiplex. From 1993 to 2012, all pools of all mosquitoes, except $C x$. pipiens and $C x$. restuans, were tested on Vero cell culture. If a pool of $C x$. pipiens and $C x$. restuans tested positive by RT-PCR, it was then tested by Vero cell culture. In all years, our specimens were tested on Vero cell culture, the sensitivity of which was not expected to change. The consistent use, throughout this surveillance, of a standard culture method means the presence of EEEV in any year is not negated by the addition or modification of a RT-PCR assay.

\section{Conclusions}

This was the first time in NYS that EEEV was detected in Cx. salinarius, Ps. ferox and An. punctipennis. The detection of EEEV in mosquitoes every year for 10 years was the longest time span since surveillance began in 1971. This was preceded by a period of five years of no EEEV detections. The calendar date of the earliest annual appearance of EEEV in mosquitoes did not change during surveillance spanning 42 years.

\footnotetext{
Acknowledgements

We appreciate the work of the staff of the departments of health of the participating counties. We are grateful to the staff of the Suffolk County Arthropod-Borne Disease Laboratory and the Division of Vector Control for assistance in mosquito and arboviral surveillance efforts. We thank staff of the Arbovirus Laboratory, Wadsworth Center, Department of Health, State of New York, for culture and nucleic acid testing. We appreciate the support of P. Bryon Backenson, Director, Vector Surveillance Unit, Bureau of Communicable Disease Control, Department of Health, State of New York; David C. Brittain, Director, Central New York Regional Office, Department of Health, State of New York; and William Snyder, Professor and Chair, Environmental Sciences Department, School of Agriculture and Natural Resources, Morrisville State College, State University of New York.
}

\section{Funding}

This work was supported by Cooperative Agreements NU50CK000423 and U01CK000509 funded by the Centers for Disease Control and Prevention. Its contents are solely the responsibility of the authors and do not necessarily represent the official views of the Centers for Disease Control and Prevention or the Department of Health and Human Services. Funding included full-time salaries in the Department of Health of the State of New York. The observations, reasonings or inferences presented here are not to be construed as official findings, determinations or policies of the Department of Health of the State of New York. 


\section{Availability of data and materials}

All data generated or analyzed during this study are included in this published article.

\begin{abstract}
Authors' contributions
JO designed study in part, collected data in part, collated data, designed tables, interpreted results, placed results in context of previously published work, pointed out limitations of study, proposed practical applications, refined manuscript. GL analyzed data, refined manuscript. JK collected and provided data from Sullivan County. SRC provided data from Suffolk County, refined manuscript. LDK oversaw laboratory arbovirus testing, refined manuscript. JAS designed study in part, analyzed data, produced tables and figures, proposed practical applications, refined manuscript. JJH conceived study in part, collected data in part, designed figures, placed results in context of previously published work, refined manuscript. All authors read and approved the final manuscript.
\end{abstract}

\section{Ethics approval and consent to participate}

Not applicable.

\section{Consent for publication}

Not applicable.

\section{Competing interests}

The authors declare that they have no competing interests.

\section{Publisher's Note}

Springer Nature remains neutral with regard to jurisdictional claims in published maps and institutional affiliations.

\section{Author details}

${ }^{1}$ Department of Health, Central New York Regional Office, State of New York, 217 South Salina Street, Syracuse, NY 13202, USA. ${ }^{2}$ School of Agriculture and Natural Resources, Morrisville State College, State University of New York, 80 Eaton Street, Morrisville, NY 13408, USA. ${ }^{3}$ Division of Epidemiology, Department of Health, Vector Surveillance Unit, Bureau of Communicable Diseases, State of New York, Room 651, Corning Tower, Empire State Plaza, Albany, NY 12237, USA. Vector Surveillance Unit, Louis Calder Center, Fordham University, 53 Whippoorwill Road, Armonk, NY 10504, USA. ${ }^{5}$ Arthropod-Borne Disease Laboratory, Suffolk County Department of Health Services, 360 Yaphank Avenue, Suite 2A, Yaphank, NY 11980, USA. ${ }^{6}$ Arbovirus Laboratory, Division of Infectious Diseases, Wadsworth Center, Department of Health, State of New York, 5668 State Farm Road, Slingerlands, NY 12159, USA. ${ }^{7}$ School of Public Health, University at Albany, State University of New York, One University Place, Rensselaer, NY 12144, USA.

Received: 3 January 2018 Accepted: 13 June 2018

Published online: 25 June 2018

\section{References}

1. Howard JJ, Wallis RC. Infection and transmission of Eastern equine encephalomyelitis virus with colonized Culiseta melanura (Coquillett). Am J Trop Med Hyg. 1974;23:522-5.

2. Nasci RS, Edman JD. Blood-feeding patterns of Culiseta melanura (Diptera: Culicidae) and associated sylvan mosquitoes in southeastern Massachusetts Eastern equine encephalitis enzootic foci. J Med Entomol. 1981;18:493-500.

3. Molaei G, Oliver J, Andreadis TG, Armstrong PM, Howard JJ. Molecular identification of blood-meal sources in Culiseta melanura and Culiseta morsitans from an endemic focus of Eastern equine encephalitis virus in New York. Am J Trop Med Hyg. 2006;75:1140-7.

4. Apperson CS, Hassan HK, Harrison BA, Savage HM, Aspen SE, Farajollahi A, et al. Host feeding patterns of established and potential mosquito vectors of West Nile virus in the eastern United States. Vector Borne Zoonotic Dis. 2004:4:71-82.

5. Molaei G, Andreadis TG, Armstrong PM, Thomas MC, Deschamps T, Cuebas-Incle $E$, et al. Vector-host interactions and epizootiology of Eastern equine encephalitis virus in Massachusetts. Vector Borne Zoonotic Dis. 2013;13:312-23.

6. Hayes RO, Beadle LD, Hess AD, Sussman O, Bonese MJ. Entomological aspects of the 1959 outbreak of Eastern encephalitis in New Jersey. Am J Trop Med Hyg. 1962;11:115-21.
7. Howard JJ, Grayson MA, White DJ, Morris CD. Eastern equine encephalitis in New York State. J Florida Mosq Control Assoc. 1994;65:1-7.

8. Nasci RS, Mitchell CJ. Arbovirus titer variation in field-collected mosquitoes. J Am Mosq Control Assoc. 1996;12:167-71.

9. Armstrong PM, Andreadis TG. Eastern equine encephalitis virus in mosquitoes and their role as bridge vectors. Emerg Infect Dis. 2010;16:1869-74.

10. Chamberlain RW, Sikes RK, Nelson DB, Sudia WD. Studies on the North American arthropod-borne encephalitides VI. Quantitative determinations of virus-vector relationships. Am J Trop Med Hyg. 1954;60:278-85.

11. Morris CD, Whitney E, Bast TF, Deibel R. An outbreak of Eastern equine encephalomyelitis in upstate New York during 1971. Am J Trop Med Hyg. 1973;22:561-6.

12. Morris CD, Caines AR, Woodall JP, Bast TF. Eastern equine encephalomyelitis in upstate New York, 1972-1974. Am J Trop Med Hyg. 1975;24:986-91.

13. Srihongse S, Grayson MA, Morris CD, Deibel R, Duncan CS. Eastern equine encephalomyelitis in upstate New York: studies of a 1976 epizootic by a modified serologic technique, hemagglutination reduction, for rapid detection of virus infections. Am J Trop Med Hyg 1978;27:1240-5

14. Zaki MH. Arthropod-borne viral encephalitides: Illusion or reality in Suffolk County? N Y State J Med. 1979;79:902-3.

15. Rochlin I, Harding K, Ginsberg HS, Campbell SR. Comparative analysis of distribution and abundance of West Nile and eastern equine encephalomyelitis virus vectors in Suffolk County, New York, using human population density and land use/cover data. J Med Entomol. 2008;45:563-71.

16. Howard JJ, Grayson MA, White DJ, Oliver J. Evidence for multiple foci of Eastern equine encephalitis virus (Togaviridae: Alphavirus) in central New York State. J Med Entomol. 1996:33:421-32.

17. Lukacik GL, Anand M, Shusas EJ, Howard JJ, Oliver J, Chen H, et al. West Nile virus surveillance in mosquitoes in New York State, 2000-2004. J Am Mosq Control Assoc. 2006;22:264-71.

18. Newhouse VR, Chamberlain RW, Johnson JG, Sudia WD. Use of dry ice to increase mosquito catches of CDC miniature light trap. Mosq News. 1966; 26:30-5.

19. Reiter P. A portable battery-powered trap for collecting gravid Culex mosquitoes. Mosq News. 1983:43:496-8.

20. Morris CD. A structural and operational analysis of diurnal resting shelters for mosquitoes (Diptera: Culicidae). J Med Entomol. 1981;18:419-24.

21. Moore CG, McLean RG, Mitchell CJ, Nasci RJ, Tsai TF, Calisher CH, et al. Guidelines for arbovirus surveillance programs in the United States. Fort Collins, CO, USA: United States Department of Health and Human Services. Centers for Disease Control and Prevention. 1993;

22. White DJ, Kramer LD, Backenson PB, Lukacik G, Johnson G, Oliver J, et al. Mosquito surveillance and polymerase chain reaction detection of West Nile Virus, New York State. Emerg Infect Dis. 2001;7:643-9.

23. Means RG. Mosquitoes of New York. Part I. The genus Aedes Meigen with identification keys to genera of Culicidae. Albany: New York State Museum (Bulletin 430a). 1979:1-221.

24. Means RG. Mosquitoes of New York. Part II. Genera of Culicidae other than Aedes occurring in New York. Albany: New York State Museum (Bulletin 430b). 1987;25:1-180.

25. Stojanovich CIIllustrated key to common mosquitoes of northeastern North America. Atlanta: Published by Author; 1961. p. 1-49.

26. Andreadis TG, Thomas MC, Shepard JJ. Identification guide to the mosquitoes of Connecticut. New Haven: Connecticut Agricultural Experiment Station (Bulletin 966). 2005:1-173.

27. Boromisa RD, Grayson MA. Incrimination of Aedes provocans as a vector of Jamestown Canyon virus in an enzootic focus of northeastern New York. J Am Mosq Control Assoc. 1990;6:504-9.

28. Kauffman EB, Jones SA, Dupuis AP II, Ngo KA, Bernard KA, Kramer LD. Virus detection protocols for West Nile Virus in vertebrate and mosquito specimens. J Clin Microbiol. 2003;41:3661-7.

29. Lambert AJ, Martin DA, Lanciotti RS. Detection of North American Eastern and Western equine encephalitis viruses by nucleic acid amplification assays. J Clin Microbiol. 2003;41:379-85.

30. Hull R, Nattanmai S, Kramer LD, Bernard KA, Tavakoli NP. A duplex real-time reverse transcriptase polymerase chain reaction assay for the detection of St. Louis encephalitis and Eastern equine encephalitis viruses. Diagn Microbiol Infect Dis. 2008;62:272-9. 
31. Lanciotti RS, Roehrig JT, Deubel V, Smith J, Parker M, Steele K, et al. Origin of the West Nile Virus responsible for an outbreak of encephalitis in the northeastern United States. Science. 1999;286:2333-7.

32. Howard JJ, Morris CD, Emord DE, Grayson MA. Epizootiology of Eastern equine encephalitis virus in upstate New York, USA. VII. Virus surveillance 1978-85, description of 1983 outbreak, and series conclusions. J Med Entomol. 1988;25:501-14.

33. Takeda T, Whitehouse CA, Brewer M, Gettman AD, Mather TN. Arbovirus surveillance in Rhode Island: assessing potential ecologic and climatic correlates. J Am Mosq Control Assoc. 2003;19:179-89.

34. Markowski D. Eastern equine encephalitis outbreak 1996: what really happened in Rhode Island. In, Proceedings of the 42nd Annual Meeting of the Northeastern Mosquito Control Association, 1996. 9-11 December 1996. Mystic, Connecticut. http://www.nmca.org/paper6a.htm. Accessed 25 Mar 2018.

35. Andreadis TG, Anderson JF, Tirrell-Peck SJ. Multiple isolations of Eastern equine encephalitis and highlands J viruses from mosquitoes (Diptera: (ulicidae) during a 1996 epizootic in southeastern Connecticut. J Med Entomol. 1998;35:296-302.

36. Oliver J, Lukacik G, Kramer LD, Backenson PB, Sherwood JA, Howard JJ. Geography and timing of cases of Eastern equine encephalitis in New York State from 1992 to 2012. Vector Borne Zoonotic Dis. 2016;16:283-9.

37. Edman JD, Timperi $R$, Werner B. Epidemiology of Eastern equine encephalitis in Massachusetts. J Florida Mosq Control Assoc. 1993;64:84-96.

38. Hachiya M, Osbourne M, Stinson C, Werner BG. Human Eastern equine encephalitis in Massachusetts: predictive indicators from mosquitoes collected at 10 long-term trap sites, 1979-2004. Am J Trop Med Hyg. 2007;76:285-92.

39. New Jersey Agricultural Experiment Station. Vector Surveillance Reports, 1977 to 2017. Center for Vector Biology, School of Environmental \& Biological Sciences, Rutgers, The State University of New Jersey, New Brunswick, New Jersey. http://vectorbio.rutgers.edu/reports/vector/. Accessed 25 Mar 2018

40. Connecticut Agricultural Experiment Station. State of Connecticut Mosquito Trapping and Arbovirus Testing Program-Historical Information, 1998 to 2016. New Haven, Connecticut. http://www.ct.gov/caes/cwp/view.asp?a= 2819\&q=552822. Accessed $25 \mathrm{Mar} 2018$

41. Hayes RO, Doane OW Jr. Primary record of Culiseta melanura biting man in nature. Mosq News. 1958;18:216-7.

42. Wallis RC. Recent advances in research on the Eastern encephalitis virus. Yale J Biol Med. 1971;37:413-21.

43. Cupp EW, Tennessen KJ, Oldland WK, Hassan HK, Hill GE, Katholi CR, et al. Mosquito and arbovirus activity during 1997-2002 in a wetland in northeastern Mississippi. J Med Entomol. 2004;41:495-501.

44. Wozniak A, Dowda HE, Tolson MW, Karabatsos N, Vaughan DR, Turner PE, et al. Arbovirus surveillance in South Carolina, 1996-98. J Am Mosa Control Assoc. 2001;17:73-8.

45. Nasci RS, Berry RL, Restifo RA, Parsons MA, Smith GC, Martin DA. Eastern equine encephalitis virus in Ohio during 1991. J Med Entomol. 1993;30:217-22.

46. Moncayo AC, Edman JD. Toward the incrimination of epidemic vectors of eastern equine encephalomyelitis virus in Massachusetts: abundance of mosquito populations at epidemic foci. J Am Mosq Control Assoc. 1999:15:479-92.

47. Vaidyanathan R, Edman JD, Cooper LA, Scott TW. Vector competence of mosquitoes (Diptera: Culicidae) from Massachusetts for a sympatric isolate of Eastern equine encephalomyelitis virus. J Med Entomol. 1997;34:346-52.

48. Scherer WF, Dickerman RW, Diaz-Najera A, Ward BA, Miller MH, Schaffer PA Ecologic studies of Venezuelan encephalitis virus in southeastern México III. Infection of mosquitoes. Am J Trop Med Hyg. 1971;20:969-79.

Ready to submit your research? Choose BMC and benefit from:

- fast, convenient online submission

- thorough peer review by experienced researchers in your field

- rapid publication on acceptance

- support for research data, including large and complex data types

- gold Open Access which fosters wider collaboration and increased citations

- maximum visibility for your research: over $100 \mathrm{M}$ website views per year

At BMC, research is always in progress.

Learn more biomedcentral.com/submissions 